\title{
IFIP Working Group 3.2: the place of computing in higher education
}

\author{
Bernard Levrat \\ Chair of IFIP Working Group 3.2 \\ Centre Universitaire d'Informatique \\ Geneva \\ Switzerland
}

\begin{abstract}
In this paper a brief history of the early work of IFIP Working Group 3.2 and current activities on curriculum development are reviewed. Computing has become part of many disciplines. Networked computers now make scientific visualization and multimedia applications possible. What impact will these have on higher education, both in traditional university and in open learning situations? How should ethical issues deriving from the profound influence of Information Technologies on everyday life be taught? Working Group 3.2 aims clearly at a moving target. The WG 3.2 Professional Groups at this world conference should help in defining key activities to be pursued in the near future.
\end{abstract}

Main conference themes: informatics as study topic, information technology, social issues

Educational areas: higher education

Study topics: computer science/informatics

Secondary keywords: computer assisted instruction, computing, curriculum development, multimedia 


\section{INTRODUCTION}

Founded in 1968, IFIP Working Group 3.2 (WG 3.2) was chaired from 1968 to 1978 by Prof. R. A. Buckingham who concentrated its activities on 'Information systems' and on the education of 'Information System Designers'. In 1977 a joint working conference was organized by IFIP Technical Committee 3 (TC 3 ) on education, the umbrella organization of the educational working groups within IFIP, and TC 8 (Information Systems) with the title "Education and large information systems" [1]. An International Curriculum for Information System Designers was also published around that time.

In a dormant state from 1978 to 1983 , WG 3.2 was revived by Prof. W. A. Atchison who got fame as one of the authors of Curriculum' 68 for the purpose of adapting curricula for computer science majors and, foremost, for studying the best ways to make computers useful in the teaching of other disciplines. In 1987 a working conference was held in Delft on "A computer for each student and its impact on teaching and curriculum in the University" [2].

In 1988 a special meeting held in Lausanne during the European Conference on Computers in Education (ECCE88) recognized the need to address once more the issues of the computer science curricula in higher education. The two leading American institutions, ACM and the IEEE Computer Society, had joined forces in a curriculum task force [3]. IFIP WG 3.2 felt that also the international community should devote some thought to the content of the curricula for specialists such as informaticians, computer scientists and software engineers as well as to education in 'computing' for students from other disciplines. The work of the working group in the last six years has been devoted to these ends with a critical review of the role universities play in defining what should be taught at what level and for what public.

\section{The aims of IFIP WG 3.2}

As set out in its prospectus the aims of the Working Group are:

- To promote a proper understanding of the impact of the information technologies on society and to develop an awareness of the consequent new professional responsibilities for all students.

- To keep in review the need for on-going changes in curricula for informatics resulting from changes in the emphasis put on the existing components, from technological development and from theoretical advances.

- To provide guidance on the adequate informatics component needed in the curricula of all disciplines making significant use of informatics. 
- To work on model curricula, adaptable to various cultural needs and educational systems, especially those of developing countries.

\section{COMPUTER SCIENCE IDENTITY CRISIS}

Educational institutions are confronted with an unprecedented rate of innovation. In every subject choices have to be made between running after the most recent developments or teaching fundamental concepts of lasting value which will help the student to put in perspective the avalanche of new ideas coming from the media.

Information science and technology together with informatics are potent instruments in today's world affecting people in everything, from their education and work to their leisure and in their homes. It is a powerful tool in science and engineering, in commerce and industry, in education and administration. It will be particularly subject to the kind of hype which accompanies new technological developments while the role of university education in the domain is belittled, if not deemed a waste of time and money.

One of the most frequently asked questions is whether or not Computer Science and Engineering exist as disciplines. What does informatics encompass? What are its fundamental subjects? There was a large debate in the Communications of the ACM following the publication of the work of a task force chaired by Peter J. Denning [4]. WG 3.2 contributed some confrontations and clarifications in a workshop held in April 1990 on 'Informatics Curricula for the 1990s' [5].

To quote a few contributions: there was a call to develop Computational Science bringing computer scientists to use their skills and their machines to solve problems for other disciplines. There should be opportunities to be educated as computational biologists, chemists, etc. Considering the roles of computing in economy and society it was stated that curricula in computer science should reach out to other disciplines or become irrelevant.

Much controversy arose from the discussion of the first few courses in an informatics programme. Should proof techniques and formal mathematics be used before programming is taught? Some participants emphasized the role of good design. Most felt sorry about the programming tools currently offered by industry. In the end most questions were left unanswered, even the most basic ones such as: "are we to teach a science or an engineering discipline?". Besides, unlike physics or mathematics, introductory courses for computer science majors can be used for science and engineering students, but would probably be inadequate for students of other disciplines especially the humanities. 
With more and more powerful hardware and little progress in programming tools there is much work left to be done and curriculum development will still require attention in the future.

\section{CONTENTS OF SPECIFIC COURSES}

The successful implementation of a curriculum requires good textbooks and the evaluation of different approaches for each subject. If a university has no research activity in a given area, it is hard to define the profile of teachers of a new discipline. In workshops and congresses of specialists very little time is devoted to issues about teaching. In order to help the development of a complete curriculum WG 3.2 engaged its forces on several fronts.

\section{Teaching advanced subjects in Informatics}

The contents of courses in VLSI design, software engineering, humancomputer interaction, computational mathematics, visualization and artificial intelligence were addressed in a workshop [6] held at ETH Zurich in October 1991. Compared to the meeting at Brown University there was less unity of subject since a number of advanced domains was explored and their integration in the curriculum discussed. There still remains a good deal of controversy about what the complete informatics background of a well-educated computer scientist should be.

\section{A modular curriculum in Computer Science}

In 1984, UNESCO published a booklet prepared by a small group of members of IFIP TC 3. For each subject this modular informatics curriculum gave an outline of the contents of the courses and a set of easily accessible references. It was widely distributed at the time by UNESCO. Ten years later WG 3.2 felt a responsibility to update the booklet both with respect to contents and to references. The updated version has just been published by UNESCO [7]. Such a document should not remain static for another 10 years. Volunteers within WG 3.2 have proposed to make it accessible via Internet. Permanent discussions on curricula under different circumstances could then take place on a bulletin board and be disseminated in a news group.

\section{Computing for all students}

The power of current computers, their amazing storage capacity and the realism of rendering graphical representations of models could, in the eyes of a number of educators, change the way learning is currently achieved in universities. Much tinkering is taking place without any grand design to develop model building skills, to implement mastery learning or, more generally, 
to use the computer as a partner in exploring the world, testing hypothesis and solving problems. WG 3.2 can only offer modest contributions to help shake the inertia of the establishment of conservative teachers and unconvinced politicians. It staged two events where hopes and useful, but limited, experiences were shared.

\section{Visualization in scientific computing: uses in university education}

After the Zurich meeting it was felt that there were good reasons to study computer graphics and scientific visualization from the viewpoint of the necessary relationship between computer science students and other disciplines one the one hand and from the viewpoint of students engaged in other disciplines eager to use the power of the computer. In July 1993 a working conference brought together at the University of California, Irvine, USA, key participants in the educational uses of scientific visualization in a range of disciplines (engineering, computer science, and computational sciences-chemistry, physics, biology, mathematics) to explore common problems and opportunities and to identify promising directions for future work [8].

\section{Interactive multimedia in university education}

A collection of papers has been published as a result of a working conference held at the University of Melbourne, Australia, in July 1994 [9]. Interactive multimedia is the merging of previously separate media-video, text, audio, graphics, animation — under computer control.

It claims to offer advantages over traditional computer based learning through its ability to combine stimuli for more than one of the five senses with the engaging power of interactivity. The working conference focused on the challenges of developing interactive multimedia for use in teaching and learning at university level including open university education.

The participants also engaged in the production of an interactive version of the proceedings in the form of a CD-ROM which will also be published. Many questions were raised such as:

- In what way does electronic publication add value to a print publication?

- How is information enhanced by interactivity?

- Are hypertext links and multiple forms of media sufficient?

- What is a suitable interface metaphor?

- What are the copyright concerns?

\section{University computing and network infrastructure}

Never the subject of a working conference, the theme of how to provide service, maintenance, connectivity and expert advice to a large group of users 
such as a university community has been a hot subject in several IFIP Congresses. With the leading role of universities in the use of Internet and of UNIX-based systems, the experience gained in managing advanced facilities are of interest not only to other universities, but also to the whole computing industry.

\section{FUTURE ACTIVITIES}

As indicated by the sample of activities mentioned above one can see that WG 3.2 is multifocus by nature. It cannot possibly tackle all the issues related to the use of computers in education at university level. Many topical conferences for specialists will attract educators along with experts in fields such as Artificial Intelligence, Software Engineering, Graphical Arts or Musical composition, to cite but a few examples. WG 3.2's mission is not to compete with these events.

On the other hand the whole extent of the significance of some developments for education needs to be explored. If there is enough motivation with a few individuals, if local support is available and if it is felt that an event is of general interest, the leadership of WG 3.2 will do its best to make it happen. Some working conferences have already been planned:

\section{Computers and society}

A joint TC 3/TC 9 (Technical Committee on computers and society) open conference on the place of ethical issues in the different curricula is planned in Israel in 1996. The technological developments which brought about 'the era of information technology', have had a great impact on our globe. These have changed the way of life in modern society. While information technology has in many ways brought progress, it has also raised the question of the critical impact which issues such as ethics, privacy and morals have upon the daily lives of ordinary citizens, workers and human beings.

Nevertheless, no educational system has yet produced an effective curriculum to enable adults to adapt to the technological applications and outcomes. Coping with these challenges cannot be left to 'chance' alone, but must be discussed and deliberated by the educational community which has the mission to lead towards a free, advanced and democratic 21 st century society.

The following topics could be part of this curriculum:

- ethics in the age of Information Technology (IT);

- information as Power;

- IT, employment and dequalification;

- continuous education and leisure time; 
- IT capabilities and limitations (robotics, expert systems, artificial intelligence);

- risks.

Another aspect of any curriculum organization is methodology: who should teach these important issues and at what age should awareness about the impacts of IT be introduced?

\section{IT in informatics learning}

Interest have been expressed to explore this subject in cooperation with SIGCSE-Special Interest Group on Computer Science and Engineering of ACM.

\section{Working conference on the informatics curriculum}

Possibilities are being investigated to organize a workshop or a working conference in 1996 in Poland as a follow-up after the Brown and Zurich activities.

Other activities, making use of the new technologies are also being considered. An electronic discussion on the subject of 'Reshaping of university education with IT support' has been proposed and will be moderated. The discussion should link centres throughout the world interested in the topic and may evolve into a working conference.

'Maintaining a World Wide Web server on past, current and future activities' has been offered as a possible topic. Part of this would be information on 'IT in support of academic learning networks (both in research and teaching)'. It could become a focal point for the discovery of all kinds of new services offered through the Internet.

\section{CALL FOR PARTICIPATION}

The areas where WG 3.2 intends to be active, are not limited to the above subjects. Those were proposed by the members of the Working Group duly appointed by TC 3 . As subjects become hot or cool off new proposals are welcome and can be supported. As a first step interested persons can ask to be put on our mailing list for all WG 3.2 activities or just for some of them, for example, curriculum development or the use of multimedia in education.

These persons would be expected to take an active part in some of WG 3.2 activities and they could propose their own ideas. Experienced members of WG 3.2 can give advice on working conferences, funding, publications, mailing lists, an so on. 
If you feel concerned by the place of computing in higher education and by other issues raised in the present paper, you will be welcome in the Professional Groups at the conference sponsored by WG 3.2, the working group on Informatics Education at University Level. In case you could not make it to Birmingham, use the following e-mail address to make yourself known:

levrat@uni2a.unige.ch

\section{REFERENCES}

1. Buckingham, R. A. (ed.) (1977) Education and Large Information Systems. Proceedings of IFIP Conference organized by TC 3 (Education) and TC 8 (Information Systems) in Amsterdam. North-Holland, Amsterdam.

2. Lewis, R. and Tagg, E. D. (eds.) (1987) A computer for Each Student. Proceedings of the IFIP WG 3.2 Conference on A Computer for Each Student and its Impact on Teaching and Curriculum in the University, held in Delft. North-Holland, Amsterdam.

3. ACM/IEEE CS Joint Curriculum Task Force (1991) Computing Curricula, 1991. ACM Press and IEEE-CS Press, New York.

4. Denning, P. J. et al. (1989) Computing as a discipline. Communications of the ACM 32 (1).

5. Wegner, P. and Lovis, F. (eds.) (1990) Informatics Curricula for the 1990s. Proceedings of the international workshop held at Brown University, Providence, Rhode Island, USA, April 1990, Special issue of Education \& Computing, $7(1,2)$ Elsevier.

6. Lovis, F. (ed.) (1993) Teaching advanced subjects in Informatics. Proceedings of the IFIP TC 3/WG 3.2 Working Conference, Zürich, Switzerland, October 1991, Special issue of Education \& Computing, 8 (4), Elsevier.

7. A modular curriculum in computer science. Produced by a working party of the International Federation for Information Processing (IFIP) under the auspices of UNESCO. UNESCO/IFIP, 1994. 
8. Franklin, S. D. and Stubberud, A. P. and Wiedeman, L. P. (eds.) (1994) University Education Uses of Visualisation in Scientific Computing. Proceedings of the IFIP WG 3.2 Working Conference on Visualization in Scientific Computing: Uses in University Education, Irvine, CA, USA, July 1993. IFIP Transactions A: Computer Science and Technology, No. 48, North-Holland, Amsterdam.

9. Beattie, K., McNaught, C. and Wills, S. (eds.). (1994) Interactive Multimedia in University Education. Proceedings of the IFIP WG3.2 Working Conference on the Design, Implementation and Evaluation of Interactive Multimedia in University Settings, Melbourne, Australia, July 1994. IFIP Transactions A: Computer Science and Technology, No. 59, North-Holland, Amsterdam. 